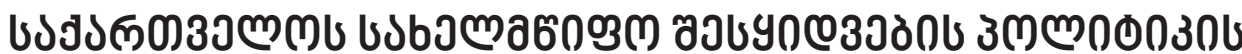

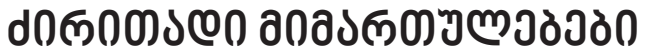

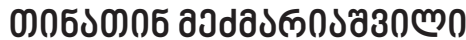

https://doi.org/10.35945/gb.2017.03.019

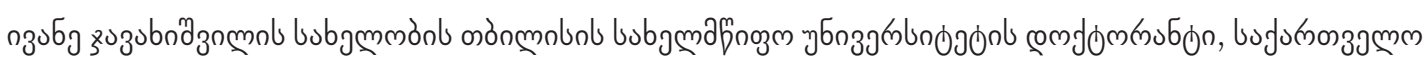

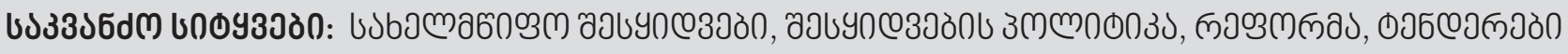

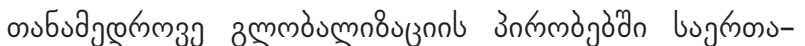

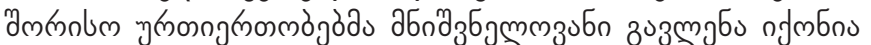

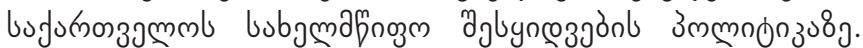

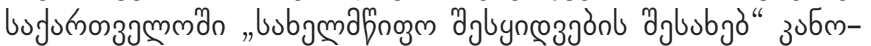

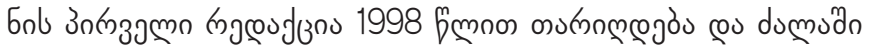

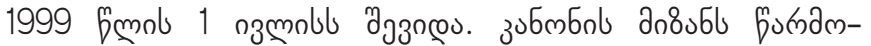

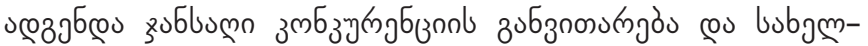

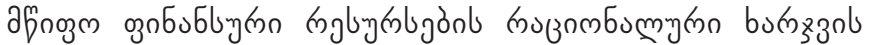

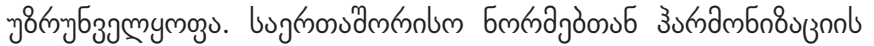

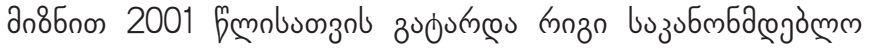

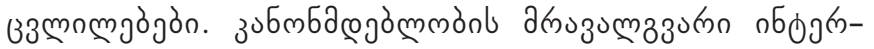

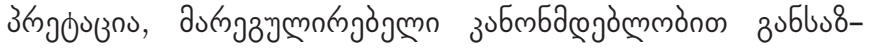

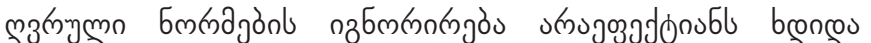

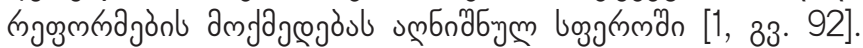

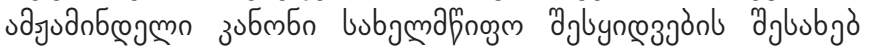

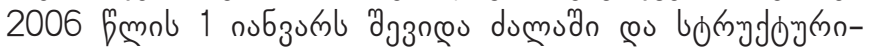

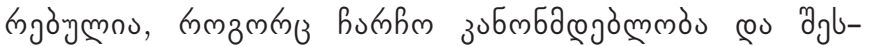

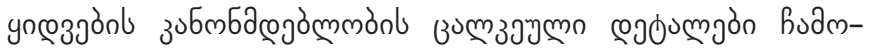

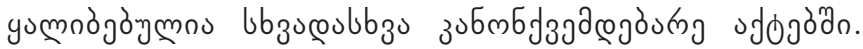

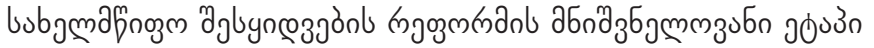

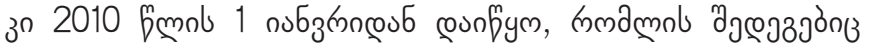

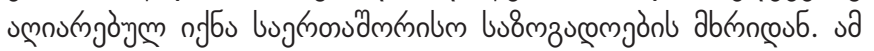

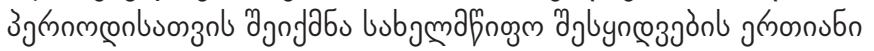

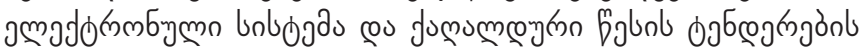

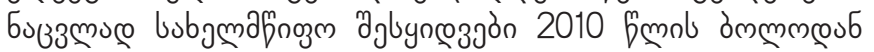

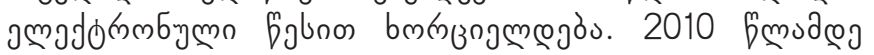

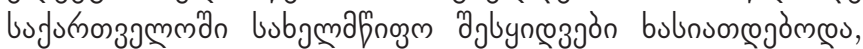

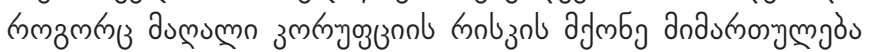

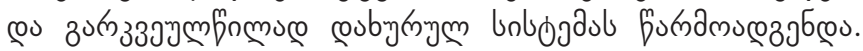

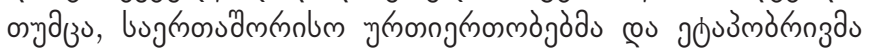

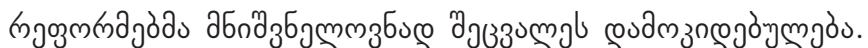

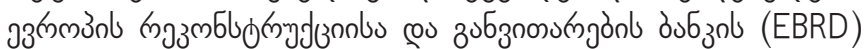

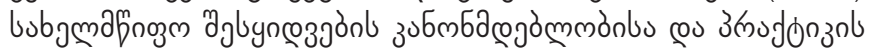

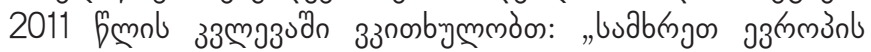

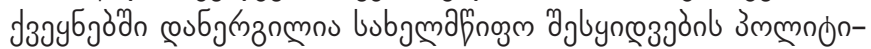

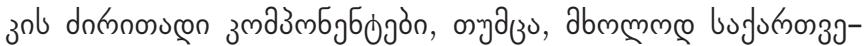

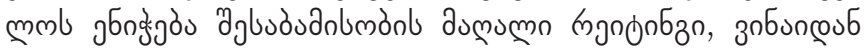

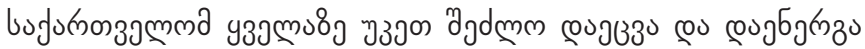

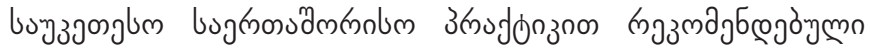

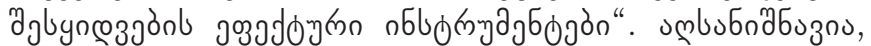

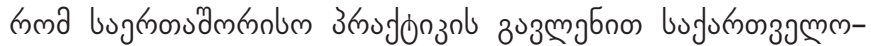

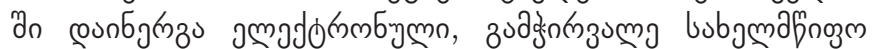

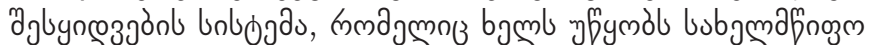

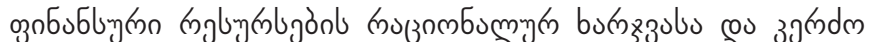

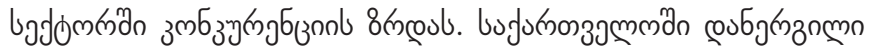

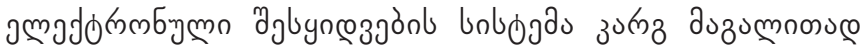

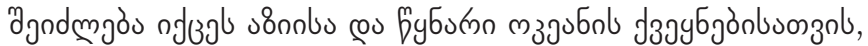

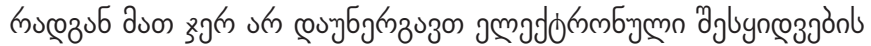

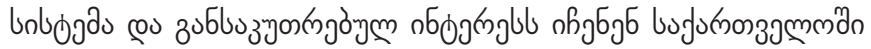

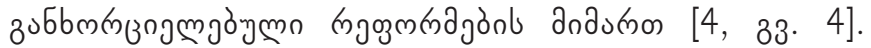

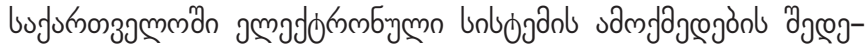

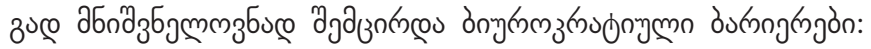

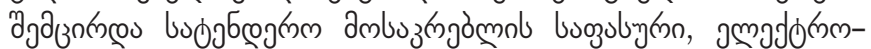

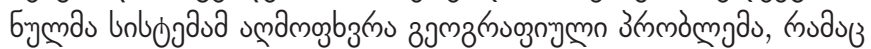

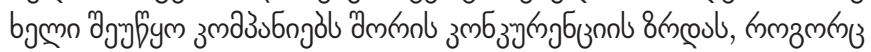

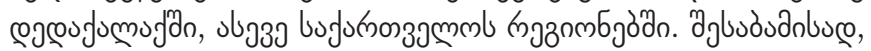

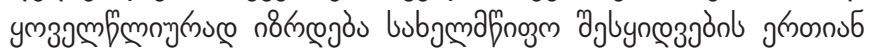

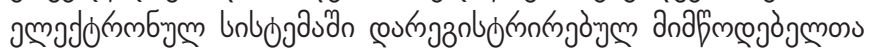

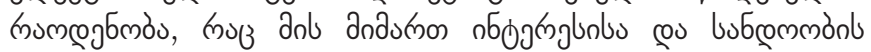

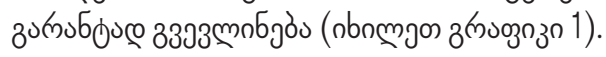

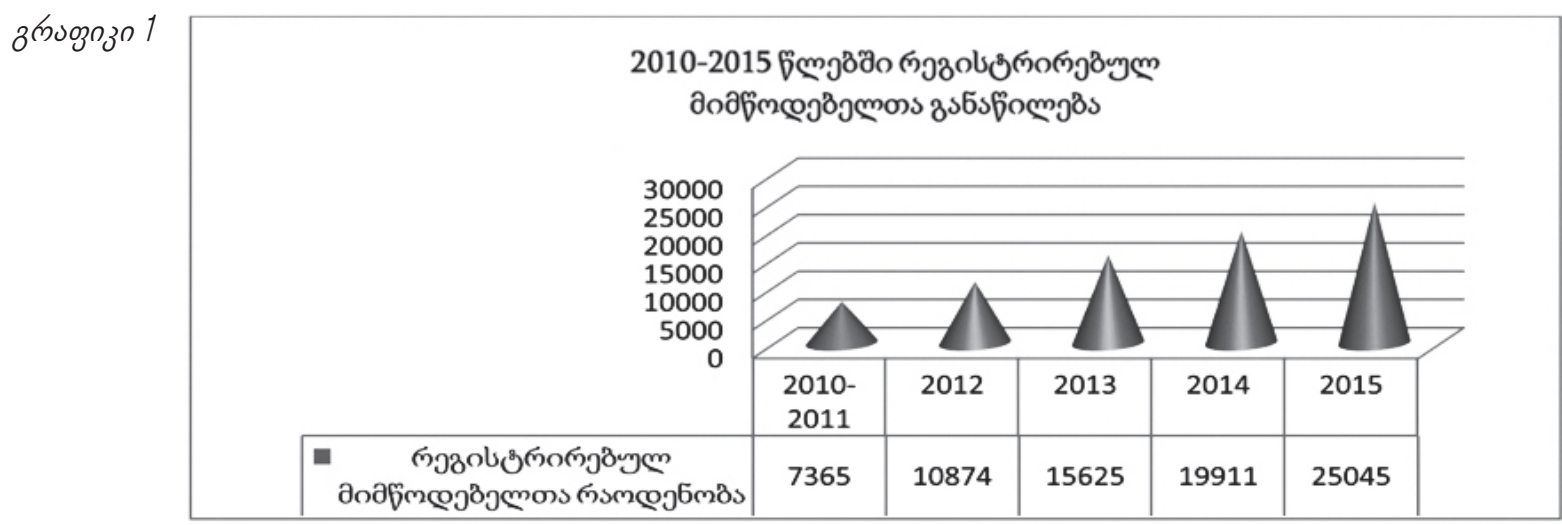

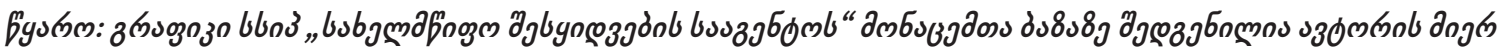




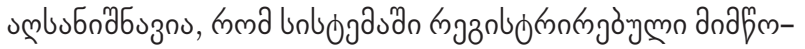

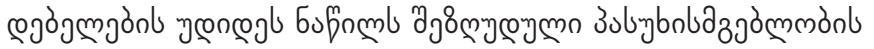

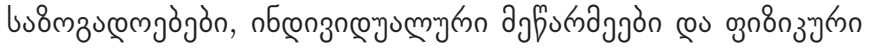

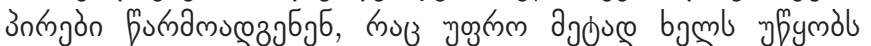

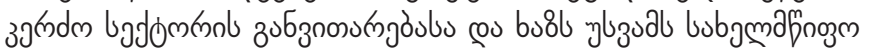

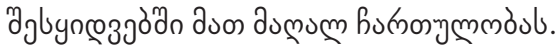

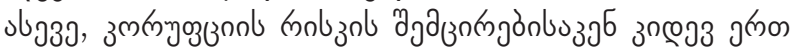

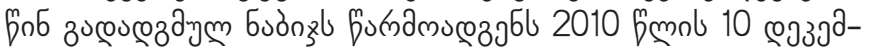

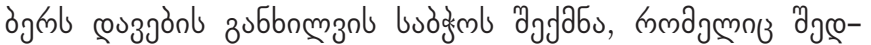

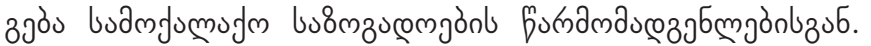

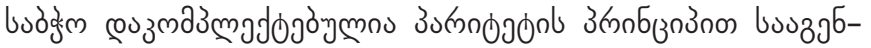

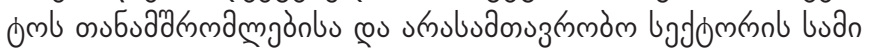

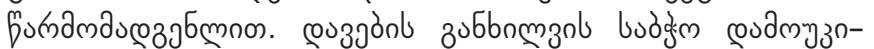

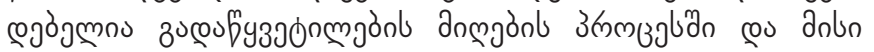

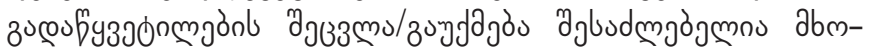

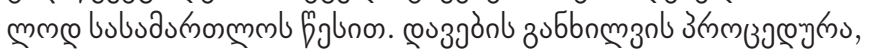

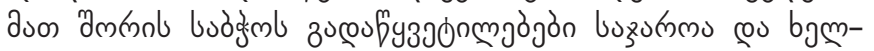

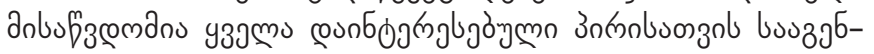

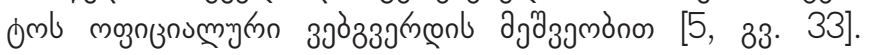

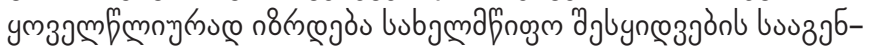

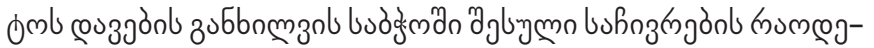

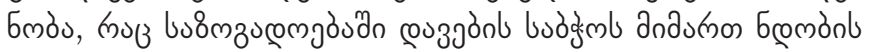

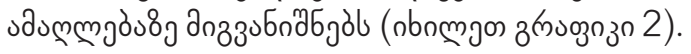

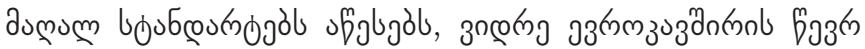

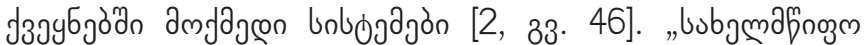

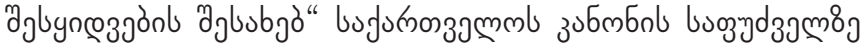

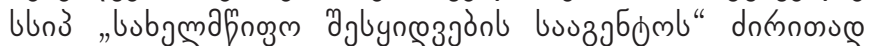

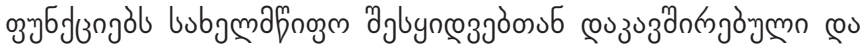

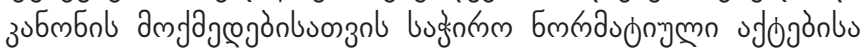

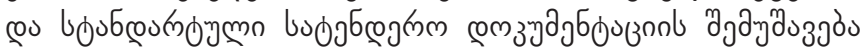

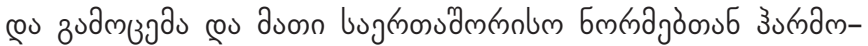

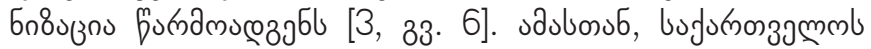

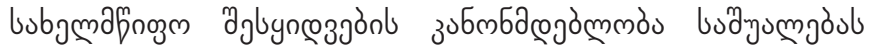

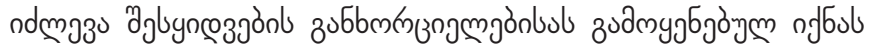

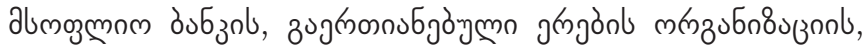

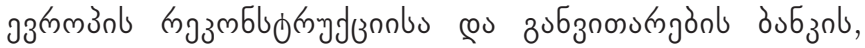

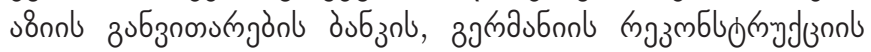

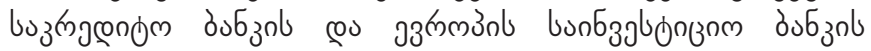

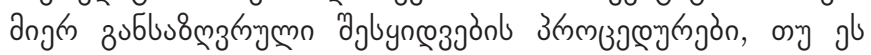

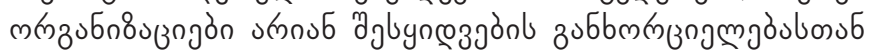

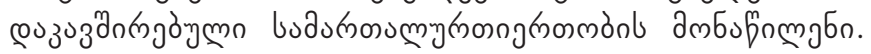
andenم

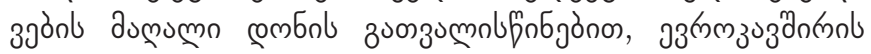

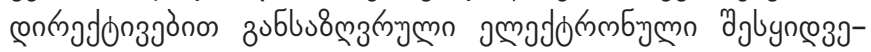

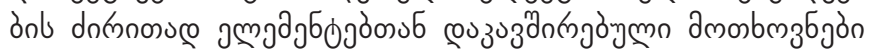

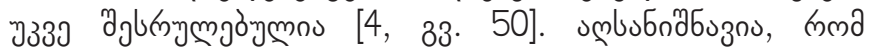

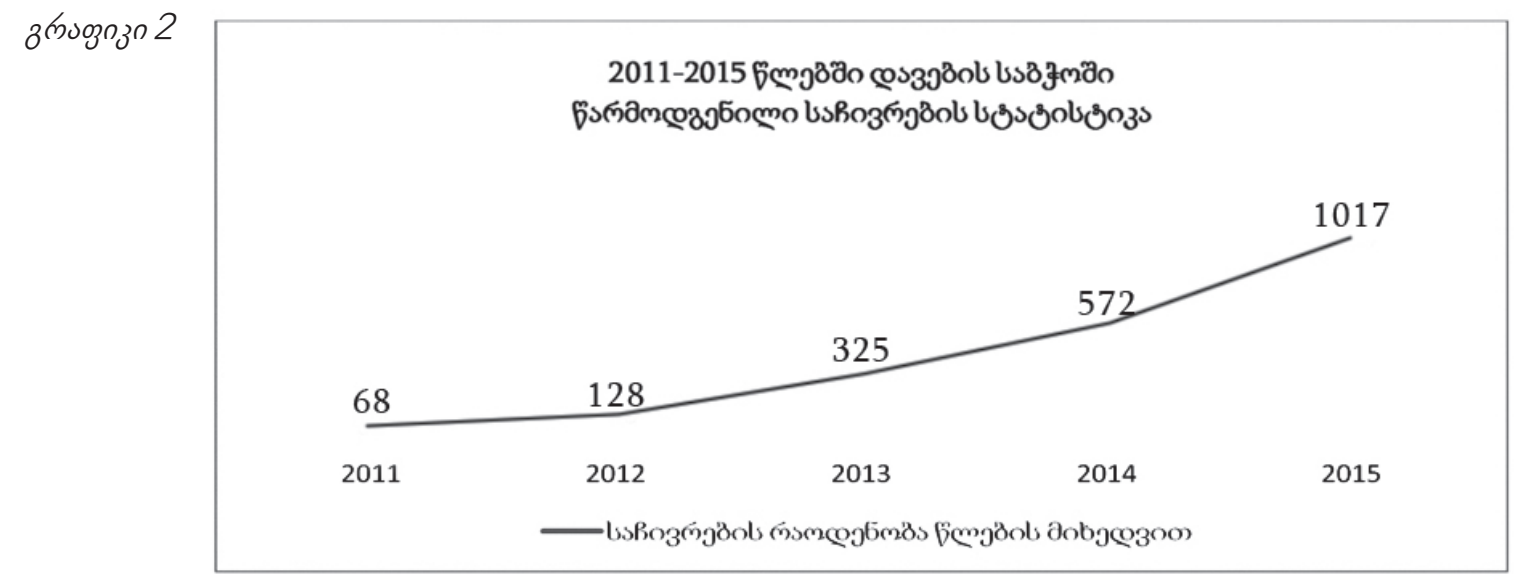

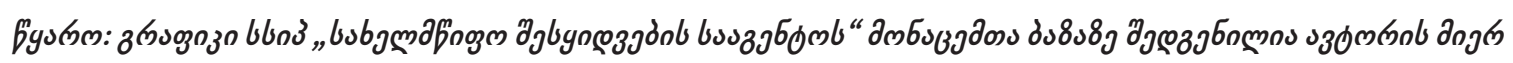

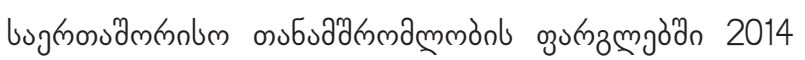

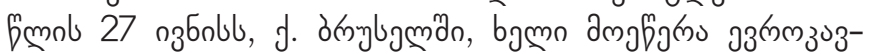

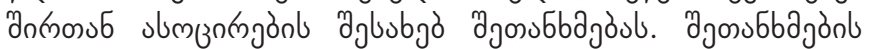

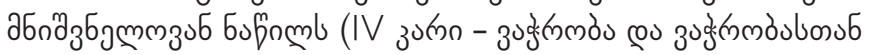

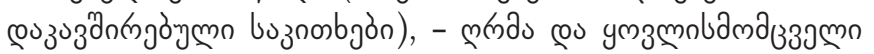

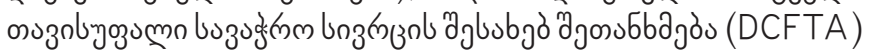

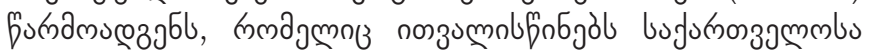

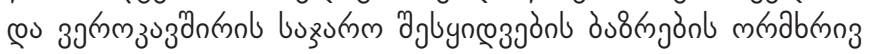

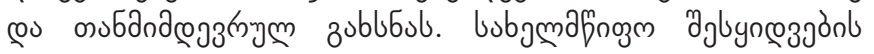

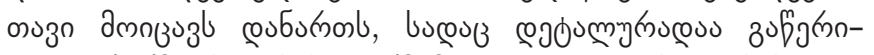

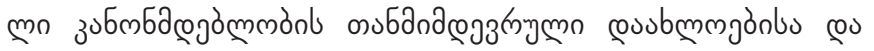

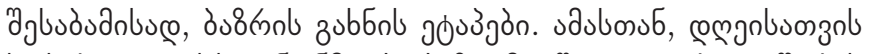

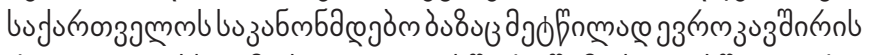

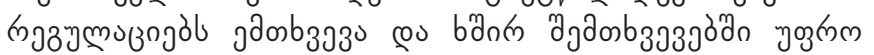

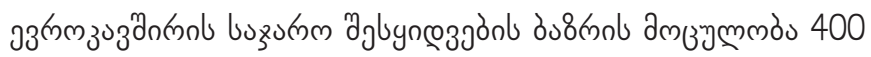

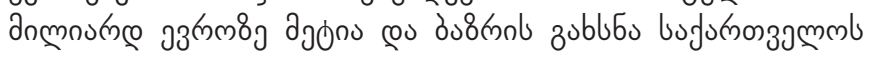

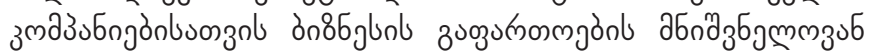

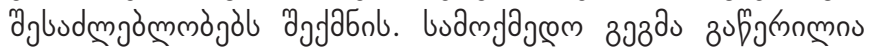

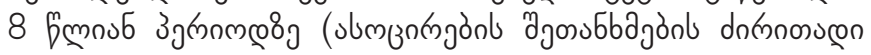

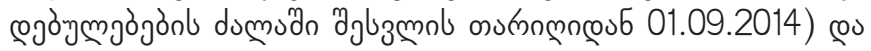

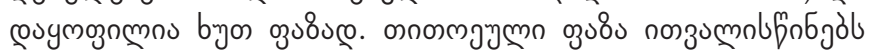

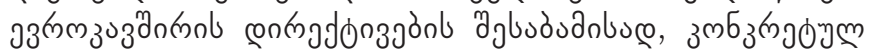

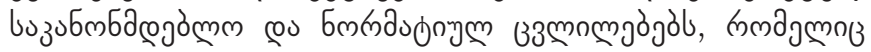

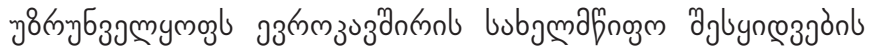
bnlojaubons6 cousbmmgasul [6, 33. 55].

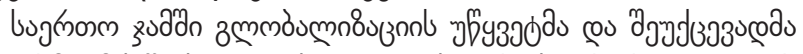

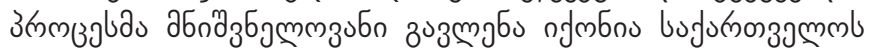

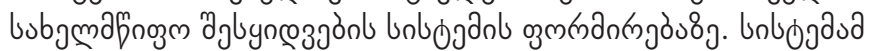




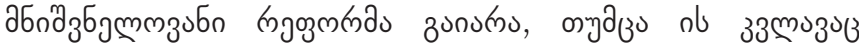

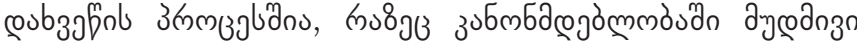

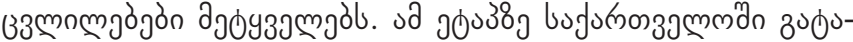

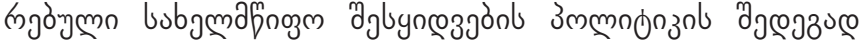

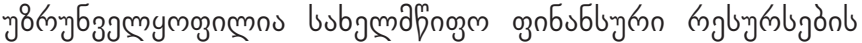

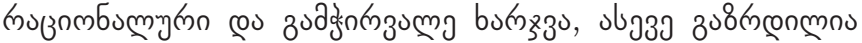

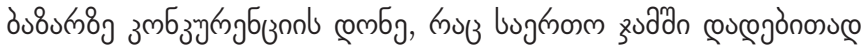

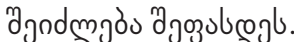

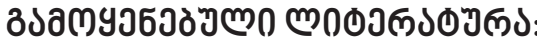

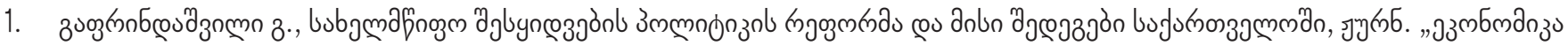

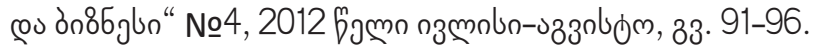

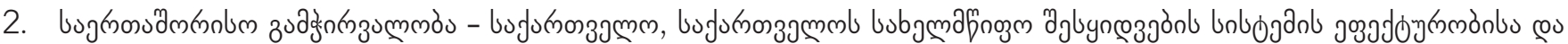

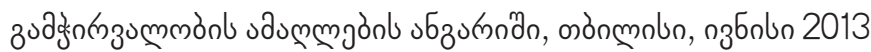

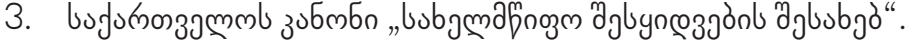

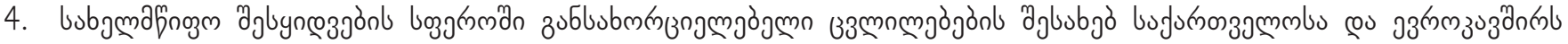

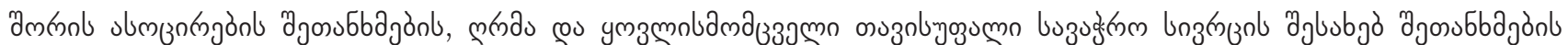

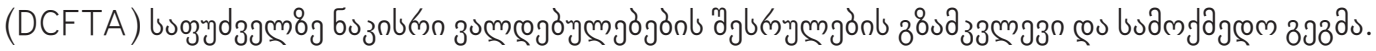

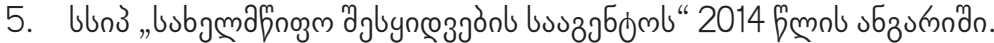

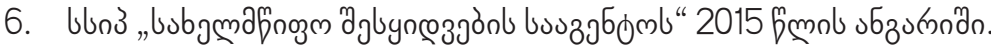




\section{BASIC DIRECTIONS OF STATE PROCUREMENT POLICY OF GEORGIA}

TINATIN MEDZMARIASHVILI

https://doi.org/10.35945/gb.2017.03.019

PhD student of Ivane Javakhishvili Tbilisi State University, Georgia

KEYWORDS: STATE PROCUREMENT, PROCUREMENT POLICY, REFORM, TENDERS

\section{SUMMARY}

The state procurement plays an important part in sustainable development of national economy. As a result of conducted reforms, the country has acquired the most transparent state procurement system during the past years, which is being permanently improved and enhanced. The continuous process of globalization had an important impact on state procurement policy. State procurement agency accomplished various arrangements within the framework of international cooperation, which will promote the further improvement of state procurement-related processes in Georgia. 